\title{
Current Status, Distribution, and Future Directions of Natural Products against Colorectal Cancer in Indonesia: A Systematic Review
}

\author{
Didi Nurhadi Illian ${ }^{1}{ }^{(0}$, Ihsanul Hafiz ${ }^{2}{ }^{\circ}$, Okpri Meila ${ }^{1}$, Ahmad Rusdan Handoyo Utomo ${ }^{3}$, Arif Nuryawan ${ }^{4,5} \oplus^{\circ}$, \\ Gontar Alamsyah Siregar ${ }^{5,6}$ and Mohammad Basyuni ${ }^{4,5, *(1)}$ \\ 1 Department of Pharmacy, Faculty of Mathematics and Natural Sciences, Universitas Syiah Kuala, \\ Banda Aceh 23111, Indonesia; illian.didinurhadi@unsyiah.ac.id (D.N.I.); okprimeila@unsyiah.ac.id (O.M.) \\ 2 Department of Pharmacology, Faculty of Pharmacy and Health, Institut Kesehatan Helvetia, \\ Medan 20124, Indonesia; ihsanulhafiz@helvetia.ac.id \\ 3 Faculty of Medicine, Universitas YARSI, Jakarta 10510, Indonesia; ahmad.rusdan@yarsi.ac.id \\ 4 Department of Forestry, Faculty of Forestry, Universitas Sumatera Utara, Medan 20155, Indonesia; \\ arif5@usu.ac.id \\ 5 Center of Excellence for Mangrove, Universitas Sumatera Utara, Medan 20155, Indonesia; gontar@usu.ac.id \\ 6 Department of Internal Medicine, Division of Gastroenterology-Hepatology, Faculty of Medicine, Universitas \\ Sumatera Utara, Medan 20155, Indonesia \\ check for \\ updates \\ * Correspondence: m.basyuni@usu.ac.id; Tel.: +62-61-8201920
}

Citation: Illian, D.N.; Hafiz, I.;

Meila, O.; Utomo, A.R.H.;

Nuryawan, A.; Siregar, G.A.;

Basyuni, M. Current Status,

Distribution, and Future Directions of

Natural Products against Colorectal

Cancer in Indonesia: A Systematic

Review. Molecules 2021, 26, 4984.

https://doi.org/10.3390/

molecules 26164984

Academic Editors:

Nadine Kretschmer and

Maurizio Battino

Received: 30 June 2021

Accepted: 13 August 2021

Published: 17 August 2021

Publisher's Note: MDPI stays neutral with regard to jurisdictional claims in published maps and institutional affiliations.

Copyright: (๑) 2021 by the authors. Licensee MDPI, Basel, Switzerland. This article is an open access article distributed under the terms and conditions of the Creative Commons Attribution (CC BY) license (https:// creativecommons.org/licenses/by/ $4.0 /)$.

\begin{abstract}
In 2020, an estimated 19.3 million new cancer cases and nearly 10 million cancer deaths have occurred worldwide, with colorectal cancer ranking as the third most frequently diagnosed $(10.0 \%)$. Several attempts have been conducted against cancer, including surgery, radiation, monoclonal antibodies, and chemotherapy. Many people choose natural products as alternatives against cancer. These products will not only help in human life preservation but also work as a source of up-to-date information, leading people away from incorrect information. We discuss the current status, distribution, and future implications of protecting populations with natural products as an alternative against colorectal cancer in Indonesia. Thirty-eight studies were included in this review for data extraction. The distribution of natural products in Indonesia that have potential activity against colorectal cancer cells was predominated by terpenoids, followed by phytosterols, phenolics, alkaloids, and polyisoprenoids. The type of cell line utilized in the cytotoxic activity analysis of natural products was the WiDr cell line, followed by HT-29 cells and HCT-116 cells. This review showed that MTT in vitro assay is a general method used to analyze the cytotoxic activity of a natural product against colorectal cancer cells, followed by other in vitro and in vivo methods. The systematic review provided predictions for several secondary metabolites to be utilized as an alternative treatment against colorectal cancer in Indonesia. It also might be a candidate for a future co-chemotherapy agent in safety, quality, and standardization. In addition, computational methods are being developed to predict the drug-likeness of compounds, thus, drug discovery is already on the road towards electronic research and development.
\end{abstract}

Keywords: colorectal cancer; WiDr; MTT; natural product; polyisoprenoids; terpenoids; Indonesia

\section{Introduction}

Cancer is a deadly disease that has become a burden to everyone. There were 9.8 million cancer deaths reported in 2018. Colorectal cancer (CRC) is the third most common type of cancer globally, with 1.80 million cases, and it ranks second with the highest mortality in the world, i.e., 862,000 deaths [1]. The increase in CRC in developing countries is possibly due to an increase in the aging population, modern living habits, dietary habits, and an increase in risk factors for CRC, which include genetic diseases, smoking, alcohol, and lack of exercise. The percentage of CRC deaths in Indonesia in 2014 was 10\% of the 
103,000 CRC mortality rates in men and $8.5 \%$ of the 92,000 in women [2,3]. In Indonesia, $\mathrm{CRC}$ is an interesting case. For instance, the median age of colorectal cancer patients is younger than the western population. This means that productive young people are affected more, thus posing a heavy economic burden on their families [4-6].

Cancer treatment with chemotherapy agents is still an option, but the multi-drug resistance (MDR) mechanism has resulted in reduced efficacy of chemotherapy drugs [7]. The chemoprevention agents referred to here generally have the role of inhibiting tumor growth through cell cycle arrest mechanisms [8], stimulating apoptosis, or inhibiting the expression of proteins that play a role in MDR [9]. Various efforts are needed to develop new treatment methods for more effective therapy and prevention of degenerative diseases [10]. Alternative options such as the use of medicinal plants in the treatment of degenerative diseases can decrease any side effects [11]. Usually, lower effects may affect low efficacy, so there may be a trade-off. Therefore, there is a need to develop targeted therapy that uses super toxic plant-derived toxins as warheads that are to be conjugated to monoclonal antibodies targeting the CRC-specific antigens [12].

One of the strategies in the discovery and development of drugs for the prevention of degenerative diseases is by exploring natural products, especially plants, that have the potential to be sources of antioxidants. Plants are known to have an important role in drug discovery [13]. Natural products are secondary metabolites produced by plants, animals, and microorganisms in response to external stimulation such as changes in nutrition, infection, and competition [14].

\section{Objective of the Review}

The systematic review has the following primary review question:

- What evidence literature and data exist on the application of natural products from Indonesian plants in colorectal cancer?

The secondary review questions are:

- What are the available trends and study distribution of colorectal cancer in Indonesia?

- What are the used approaches and indicators for colorectal cancer derived from natural products in Indonesia?

- What are the challenges and gaps in the science and application of natural products in colorectal cancer in Indonesia?

\section{The Scope of the Review}

The systematic review is focused on studies that have reported the utilization of natural products in colorectal cancer in Indonesia. The data was gathered from published literature obtained through preselected bibliographic databases such as Scopus and PubMed, as well as search engines such as Google Scholar. To determine the scope of the review, this study used a globally applied standard approach for systematic review, by first defining the Population, Intervention, Comparator, and Outcome (PICO) of the review [15]. The detailed description of PICO used for this systematic review is as follows:

- Population: Colorectal cancer in Indonesia.

- Intervention: Any secondary metabolites and natural products used for colorectal cancer from Indonesian plants. These common approaches include in vitro and in vivo.

- Comparator: Any indicators used to monitor the success of anti-colorectal cancer activity by the use of natural products or secondary metabolites.

- Outcome: Inhibited colorectal cancer or no proliferation activity of colorectal cancer.

\section{Methods}

Most of the methodological steps in this systematic review follow previous systematic reviews on the health topic or pharmacy practice $[16,17]$. In addition, the reporting guidelines for systematic reviewers in the medical and health sciences are used in this systematic review report [18]. 


\subsection{Literature Search}

Before conducting a literature search in the bibliography database, we composed a search string by identifying the relevant keywords following the defined PICO. However, we only considered keywords from Population and Intervention categories to avoid the narrowed search string and reduce the number of papers. Literature searches in Scopus and PubMed were conducted by using the English search string, while we used both an English and Bahasa Indonesia search string for Google Scholar (see Tables 1 and 2). To avoid the inclusion of further irrelevant studies in Google Scholar results, we only selected the first 50 publications, following the most relevant order.

Table 1. Search string composition adopted from defined PICO with desired focus on studies from Indonesia in both English and Bahasa Indonesia.

\begin{tabular}{cccc}
\hline Language & $\begin{array}{c}\text { Geographical } \\
\text { Location }\end{array}$ & $\begin{array}{c}\text { Population Search } \\
\text { Terms }\end{array}$ & $\begin{array}{c}\text { Intervention Search } \\
\text { Terms }\end{array}$ \\
\hline English & Indonesia & $\begin{array}{c}\text { Colorectal cancer* OR } \\
\text { "colorectal cancer*" }\end{array}$ & $\begin{array}{c}\text { Secondary } \\
\text { metabolite* OR } \\
\text { natural product* }\end{array}$ \\
\hline Bahasa Indonesia & Indonesia & $\begin{array}{c}\text { "Kanker kolon" atau } \\
\text { kanker usus besar* }\end{array}$ & $\begin{array}{c}\text { Produk bahan alam* } \\
\text { atau metabolit } \\
\text { sekunder* }\end{array}$ \\
\hline
\end{tabular}

Table 2. Literature search record.

\begin{tabular}{|c|c|c|c|c|}
\hline No. & Database & Search String & $\begin{array}{l}\text { Date of Literature } \\
\text { Search }\end{array}$ & Search Results \\
\hline 1 & Scopus & $\begin{array}{l}\text { ((Indonesia) AND (natural product OR } \\
\text { secondary metabolite) AND (colorectal } \\
\text { cancer OR rectum OR colon OR bowel } \\
\text { cancer OR adenocarsinoma)) }\end{array}$ & $13 / 02 / 2021$ & 291 \\
\hline 2 & PubMed & $\begin{array}{l}\text { ((Indonesia) AND (natural product OR } \\
\text { secondary metabolite) AND (colorectal } \\
\text { cancer OR rectum OR colon OR bowel } \\
\text { cancer OR adenocarsinoma)) }\end{array}$ & $13 / 02 / 2021$ & 13 \\
\hline 3 & $\begin{array}{c}\text { Google Scholar } \\
\text { English }\end{array}$ & $\begin{array}{l}\text { ((Indonesia) AND (natural product OR } \\
\text { secondary metabolite) AND (colorectal } \\
\text { cancer OR rectum OR colon OR bowel } \\
\text { cancer OR adenocarsinoma)) }\end{array}$ & $13 / 02 / 2021$ & 50 \\
\hline 4 & $\begin{array}{l}\text { Google Scholar } \\
\text { Bahasa Indonesia }\end{array}$ & $\begin{array}{c}\text { ((Indonesia)AND (Produk alami OR } \\
\text { matabolit sekunder) AND (Kanker } \\
\text { kolorektal OR kanker usus besar OR usus } \\
\text { besar OR kolorektal OR kanker rektum)) }\end{array}$ & $13 / 02 / 2021$ & 50 \\
\hline
\end{tabular}

\subsection{Literature Screening}

The study's relevance was determined by using the inclusion criteria presented in Table 3. The studies must meet the following relevant criteria: population, intervention, comparator, and outcome of interest. After duplicates were removed from the search results, all studies went through a two-stage screening process at the combined title and abstract, and full-text levels three reviewers. All screening stages used predefined questions-formulated following PICO-to select which publications satisfy the scope of the review. 
Table 3. List of questions used for studies inclusion and exclusion during combined title and abstract, and full-text screenings.

\begin{tabular}{|c|c|c|}
\hline Screening Stages & Questions & Screening Outcome \\
\hline Title and abstract screening & $\begin{array}{l}\text { - Is the study located in Indonesia and is the natural resource from } \\
\text { Indonesia? } \\
\text { - } \quad \text { Does the study focus on colorectal cancer? } \\
\text { Does the study present an assessment of natural products? }\end{array}$ & Studies are included if satisfy all questions \\
\hline \multirow{3}{*}{ Full-text screening } & $\begin{array}{l}\text { - } \quad \text { Does the study present an anticancer agent? } \\
\text { Does the study present any dataset related to colorectal cancer? } \\
\text { - } \quad \text { Does the study consider cytotoxic activity? } \\
\text { - Does the study consider a compound target of natural products? }\end{array}$ & \multirow{3}{*}{$\begin{array}{c}\text { Studies are included if satisfy at least two screening } \\
\text { questions }\end{array}$} \\
\hline & $\begin{array}{l}\text { For included studies, additional following open questions are given to } \\
\text { identify general information of the studies: }\end{array}$ & \\
\hline & $\begin{array}{l}\text { - Publication type (e.g., J: journal article, P: proceeding conference, } \\
\text { T: thesis, B: book chapter, R: report) } \\
\text { What is the type of study? (L: Laboratory, R: review, RS: remote } \\
\text { sensing, O: Opinion) } \\
\text { - What datasets presented in the study are relevant to review? }\end{array}$ & \\
\hline
\end{tabular}

\subsection{Reporting and Presentation}

The reporting and presentation of the results of this systematic review followed a standardized reporting approach for the systematic review of health and pharmacy studies [16-18]. A database containing systematic review screening results is complementarily presented in addition to the report.

\section{Results}

The PRISMA flow diagram of the publication screening is presented in Figure 1. Initially, 465 publications were identified through the systematic literature search string described in Table 1. Following the relevance of the initial papers to the defined research questions for this study, the literature screening, which consisted of title, abstract, and full-text screenings, resulted in 38 final papers for further data extraction. Overall, the screening processes only included $10 \%$ of the initially identified papers in Scopus, PubMed, and Google Scholar publication databases. The literature search results from major scholar databases such as Scopus as well as Google Scholar suggested the approximate publications that were recorded out of publications with duplicates (Figure 1). The cut-off date of the literature search was 13 February 2021.

As presented in Table 4, the research publication on colorectal cancer based on natural products derived from Indonesian plants has increased since 2008. The trend of publications seems to have increased significantly, starting in 2016, and it was the highest in 2018. Afterward, the positive trend continued until 2020, with the most publications in the form of journal articles.

Table 5 exhibits that the distribution of natural products having the potential activity against colorectal cancer cells in Indonesia is dominated by terpenoids, followed by phytosterols, phenolics, alkaloids, and polyisoprenoids. The type of cell line that is most often utilized in the cytotoxic activity analysis of natural products against colorectal cancer cells is the WiDr cell line (followed by HT-29 cells and HCT-116 cells). WiDr cells are human colorectal cancer cells isolated from the colon of a 78-year-old woman, a derivative of other colorectal cancer cells, namely HT-29 cells [19]. This data led to the MTT in vitro assay as a general method that was used to analyze the cytotoxic activity of a natural product against colorectal cancer cells, followed by other in vitro and in vivo methods. Commonly known anticancer methods include the MTT assay method, apoptosis, enzymatic inhibition by the in vitro method, and the use of mice and rats in the in vivo method. Azoxymethane, a metabolite of dimethyhydrazine (DMH), has been used extensively by many investigators to induce colon tumors and to study the effects of nutritional factors and chemopreventive agents in colon carcinogenesis. Azoxymethane (AOM) induces colon cancer in experi- 
mental animals; in a mechanism that is mediated by glutathione (GSH) depletion and impairing the total antioxidant capacity in colonic cells of rats [20,21]. In anticancer studies, researchers prefer the in vitro method, as can be seen from the larger research ratio than the in vivo method from results screened in the Scopus, Pubmed, and Google Scholar databases. A more complete explanation of the distribution of the types of methods, objects used, and natural products analyzed from 38 articles is summarized in Table 6.

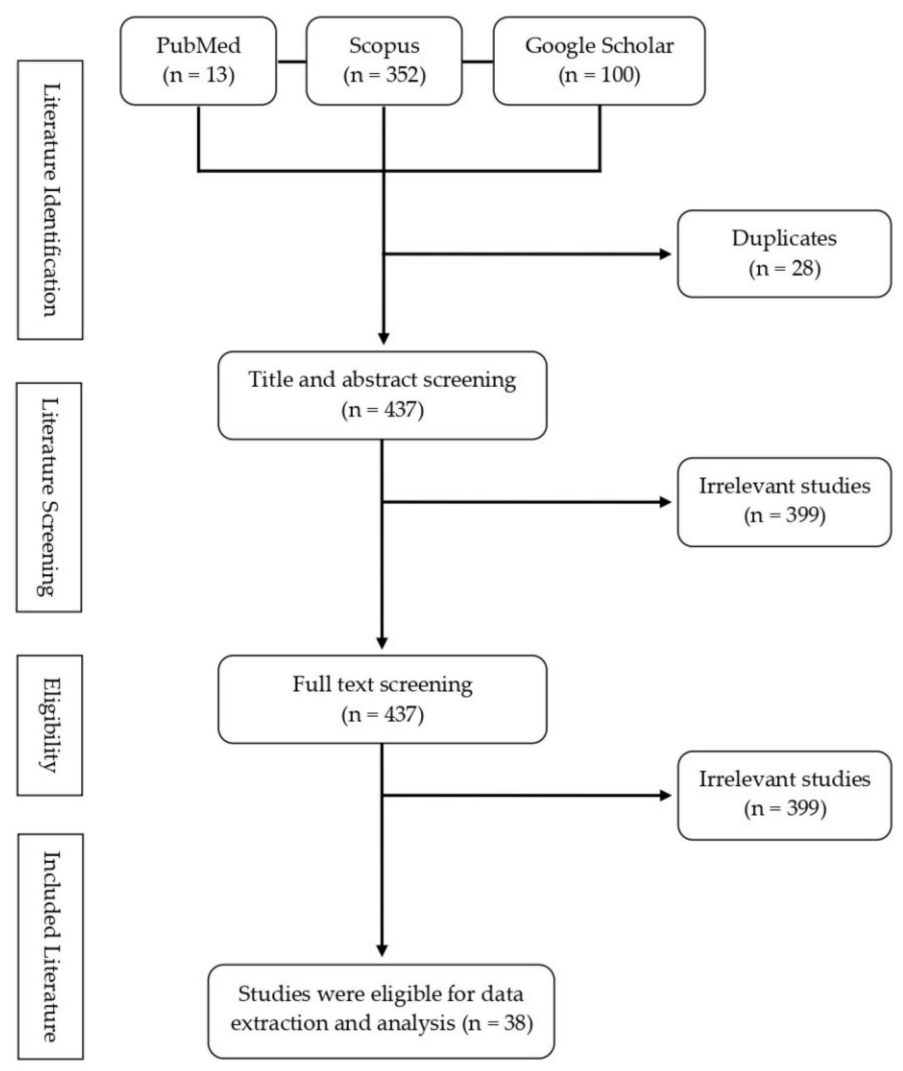

Figure 1. The PRISMA flow diagram showing the selection of eligible studies.

Table 4. The trend of publication on natural products in colorectal cancer in Indonesia: (a) year vs the number of publications; (b) types of publications reported.

\begin{tabular}{cc}
\hline Year & Number of Publication $^{\text {(a) }}$ \\
\hline 1990 & 1 \\
2007 & 1 \\
2008 & 2 \\
2012 & 2 \\
2013 & 1 \\
2015 & 2 \\
2016 & 4 \\
2017 & 5 \\
2018 & 8 \\
2019 & 7 \\
2020 & 5 \\
\hline Types of Publication & Publication Reported ${ }^{\text {(b) }}$ \\
Book/Book Chapter & 1 \\
Journal Article & 35 \\
Thesis & 2 \\
\hline
\end{tabular}


Table 5. Systematic review results summarized from 38 publications: (a) types of natural product; (b) the number of used cell lines; (c) colorectal cancer cytotoxicity analysis method.

\begin{tabular}{|c|c|}
\hline Types of Natural Product & Number of Natural Product Reported ${ }^{\text {(a) }}$ \\
\hline Phenolic & 8 \\
\hline Phytosterol & 9 \\
\hline Carotenoid & 1 \\
\hline Terpenoid & 17 \\
\hline Alkaloid & 8 \\
\hline Flavonoid & 5 \\
\hline Peptide & 3 \\
\hline Polyketide & 2 \\
\hline Polyisoprenoid & 5 \\
\hline Carbolyc acid & 1 \\
\hline Fatty acid & 5 \\
\hline Glycoside & 2 \\
\hline Aromatic compound & 1 \\
\hline Types of Cell Lines & Number of Used Cell Lines ${ }^{(b)}$ \\
\hline HCT-15 & 3 \\
\hline Colo205 & 1 \\
\hline HT-29 & 5 \\
\hline $\mathrm{CaCo}-2$ & 2 \\
\hline HCT-116 & 6 \\
\hline SW-480 & 1 \\
\hline CRC & 2 \\
\hline Colo320DM & 1 \\
\hline WiDr & 16 \\
\hline ADC & 1 \\
\hline AOM CRC Rat Model & 2 \\
\hline $\begin{array}{c}\text { Colorectal Cancer Cytotoxicity Analysis } \\
\text { Method }\end{array}$ & Number of Used Method ${ }^{(c)}$ \\
\hline MTT in vitro assay & 22 \\
\hline In vivo & 3 \\
\hline Others in vitro & 8 \\
\hline
\end{tabular}


Table 6. Systematic review results summarized from 38 publications.

\begin{tabular}{|c|c|c|c|c|c|c|c|}
\hline Types Method & $\begin{array}{l}\text { Colorectal Cancer Cytotoxic } \\
\text { Analysis Method }\end{array}$ & $\begin{array}{c}\text { Types of Object/CRC } \\
\text { Cell Lines }\end{array}$ & Types of Natural Products & $\begin{array}{l}\text { The Concentration of } \\
\text { the Tested Samples }\end{array}$ & $\begin{array}{l}\text { IC50 Value / \% Cell } \\
\text { Viability } / \% \\
\text { Inhibition }\end{array}$ & $\begin{array}{c}\text { Cytotoxicity Categorize } \\
{[22]}\end{array}$ & Mechanism of Actions \\
\hline \multirow[t]{4}{*}{ In vivo } & $\begin{array}{l}\text { Colonic lesions induced by } \\
\text { azoxymethane (AOM) }\end{array}$ & Rats & $\begin{array}{l}\text { Non-nutritive compounds in } \\
\text { fruits, vegetables, and fruits } \\
{[\text { [23] }}\end{array}$ & - & - & - & $\begin{array}{l}\text { Control of cell proliferation in ACFs } \\
\text { and/or normal-appearing crypts of } \\
\text { rats exposed to AOM [23]. }\end{array}$ \\
\hline & & Rats & $\begin{array}{l}\text { Ethanol extract of Phaleria } \\
\text { macrocarpa fruits (mostly } \\
\text { flavonoids contains) [24] }\end{array}$ & - & - & - & $\begin{array}{l}\text { The crude ethanolic extract of } P \text {. } \\
\text { macrocarpa had high antioxidant } \\
\text { activity and it modulated the } \\
\text { oxidative stress as proved by the } \\
\text { up-regulation of } \\
\text { glutathione-s-transferase and } \\
\text { superoxide dismutase [24]. }\end{array}$ \\
\hline & & Rats & $\begin{array}{l}\text { Water extract of Premna } \\
\text { oblongifolia Merr. Leaves } \\
\text { (polyphenolic compound) [25] }\end{array}$ & - & - & - & $\begin{array}{l}\text { Natural dietary fiber and } \\
\text { antioxidant sources (as found in } \\
\text { fruits, vegetables, and plant extracts) } \\
\text { may exhibit a protective effect } \\
\text { against CRC [25]. }\end{array}$ \\
\hline & $\begin{array}{l}\text { Xenograft model nude mice } \\
\text { (carrying HCT-15 cells) [26] }\end{array}$ & Mice & $\begin{array}{l}\text { Lissoclibadins (polysulfur } \\
\text { aromatic alkaloids) from } \\
\text { Ascidian lissoclinum [26] }\end{array}$ & - & - & - & $\begin{array}{l}\text { Lissoclibadin } 1 \text { suppressed tumor } \\
\text { growth in nude mice. Lissoclibadin } \\
1 \text { induced cell death via apoptosis } \\
\text { due to the mitochondrial } \\
\text { cytochrome dependent activation } \\
\text { (intrinsic pathway) of the caspase-9 } \\
\text { and caspase-3 cascade pathway [26]. }\end{array}$ \\
\hline \multirow[t]{2}{*}{ In vitro } & 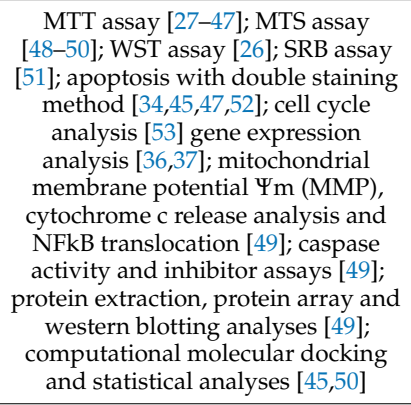 & $\begin{array}{c}\text { HT-29 [24,49,50,54]; } \\
\text { HCT-15 [26,27,43]; } \\
\text { Colo205 [48]; WiDr } \\
\text { [28,30-32,34,36- } \\
42,44,45,53] ; \text { HCT-116 } \\
\text { [29,33,35,46,47,51]; } \\
\text { CaCo-2 [49] }\end{array}$ & $\begin{array}{c}\text { Catechin 7-O-apiofuranoside } \\
\text { and didesmethyl tocotrienol } \\
{[24]}\end{array}$ & $12.5-200 \mu \mathrm{g} / \mathrm{mL}$ & $68 \%$ (inhibition) & Not classified & $\begin{array}{l}\text { The fraction of } P \text {. macrocarpa } \\
\text { exhibited the highest activity as } \\
\text { anti-proliferative against HT-29 cells. } \\
\text { The compounds had antioxidant } \\
\text { activity leading to a cytoprotective } \\
\text { effect. The mechanisms of this } \\
\text { chemoprevention included } \\
\text { up-regulation of Bax and } \\
\text { proliferation-promoting proteins } \\
\text { (PCNA) [24]. }\end{array}$ \\
\hline & & & $\begin{array}{l}\text { Lissoclibadins (polysulfur } \\
\text { aromatic alkaloids) from } \\
\text { Ascidian lissoclinum [26] }\end{array}$ & $5 \mu \mathrm{M}$ & $4.0 \mu \mathrm{M}$ & Significant / strong & $\begin{array}{l}\text { Lissoclibadin } 1 \text { exerted the most } \\
\text { potent cytotoxic effects and mainly } \\
\text { promoted apoptosis through an } \\
\text { intrinsic pathway with the } \\
\text { activation of a caspase-dependent } \\
\text { pathway in HCT-15 cells [26]. }\end{array}$ \\
\hline
\end{tabular}


Table 6. Cont.

\begin{tabular}{|c|c|c|c|c|c|c|c|}
\hline Types Method & $\begin{array}{l}\text { Colorectal Cancer Cytotoxic } \\
\text { Analysis Method }\end{array}$ & $\begin{array}{l}\text { Types of Object/CRC } \\
\text { Cell Lines }\end{array}$ & Types of Natural Products & $\begin{array}{l}\text { The Concentration of } \\
\text { the Tested Samples }\end{array}$ & $\begin{array}{l}\text { IC50 Value } / \% \text { Cell } \\
\text { Viability } / \% \\
\text { Inhibition }\end{array}$ & $\begin{array}{c}\text { Cytotoxicity Categorize } \\
{[22]}\end{array}$ & Mechanism of Actions \\
\hline & & & $\begin{array}{l}\text { Leptoclinidamide and } \\
\text { (-)-leptoclinidamine from } \\
\text { Leptoclinides dubuis [27] }\end{array}$ & 0 to $27 \mu \mathrm{M}$ & $\begin{array}{l}\text { The compounds not } \\
\text { displayed activity } \\
\text { against cell line }\end{array}$ & Not classified & $\begin{array}{l}\text { Not active against cancer cell line } \\
{[24,26] .}\end{array}$ \\
\hline & & & $\begin{array}{l}\text { Curacyclin A and B from the } \\
\text { latex of Jatropha curcas L. [48] }\end{array}$ & $1-1000 \mu \mathrm{g} / \mathrm{mL}$ & $\begin{array}{l}\text { The compounds did } \\
\text { not have any effect on } \\
\text { cell line }\end{array}$ & No cytotoxicity & \\
\hline & & & $\begin{array}{l}\text { The ethanol extracts from } 95 \\
\text { ascidians collected at North } \\
\text { Sulawesi, Indonesia; } \\
\text { shermilamine B and } \\
\text { kuanoniamine D [43] }\end{array}$ & 0 to $27 \mu \mathrm{M}$ & $\begin{array}{c}6.7 \mu \mathrm{M} \text { (shermilamine } \\
\text { B) and } 4.1 \mu \mathrm{M} \\
\text { (kuanoniamine D) }\end{array}$ & Significant / strong & $\begin{array}{c}\text { Shermilamine B and kuanoniamine } \\
\text { D was classified in the } \\
\text { pyridoacridine alkaloids, which } \\
\text { have been known to exhibit various } \\
\text { bioactivities such as cytotoxicity, } \\
\text { inhibition of topoisomerase II, } \\
\text { anti-HIV activity, } \mathrm{Ca}^{2+} \text { releasing } \\
\text { activity, and intercalation with DNA } \\
\text { [43]. }\end{array}$ \\
\hline & & & $\begin{array}{l}\text { Crude ethyl acetate extract of } \\
\text { endophytic fungi isolated from } \\
\text { Annona muricata leaves; } \\
\text { alkaloid compounds [28] }\end{array}$ & $\begin{array}{c}25 ; 50 ; 100 ; 200 ; 400 \\
\mu \mathrm{g} / \mathrm{mL}\end{array}$ & $20.80 \mu \mathrm{g} / \mathrm{mL}$ & Moderate & $\begin{array}{l}\text { Alkaloid compounds in endophytic } \\
\text { fungal extract of isolate Sir-SM2 had } \\
\text { a high cytotoxic effect on the colon } \\
\text { cancer cell and the lowest toxicity to } \\
\text { normal cells compared with other } \\
\text { fungal extracts. The compounds } \\
\text { have an alkylating activity that can } \\
\text { cause breakage and damage of DNA } \\
\text { strands, leading to the cancer cells } \\
\text { death [28]. }\end{array}$ \\
\hline & & & \multirow{3}{*}{$\begin{array}{c}\text { Fungi derived from the marine } \\
\text { sponge Neopetrosia chaliniformis } \\
\text { [38], Acanthostrongylophora } \\
\text { ingens [44], Aspergillus nomius } \\
\text { NC06 [47] }\end{array}$} & 100 ppm [38] & $\begin{array}{c}70.31 \% \text { (cell viability) } \\
\text { [38] }\end{array}$ & Not classified & $\begin{array}{l}\text { Marine-derived fungus NC06 from } \\
\text { sponge N. chaliniformis AR-01 } \\
\text { showed the most selective } \\
\text { cytotoxicity against the WiDr cell } \\
\text { line compared to the Vero cell line } \\
\text { [38]. }\end{array}$ \\
\hline & & & & $100 \mu \mathrm{g} / \mathrm{mL}[44]$ & $\begin{array}{c}12.88 \% \text { (cell viability) } \\
\text { [44] }\end{array}$ & $\begin{array}{c}\text { Strong cytotoxicity }(\leq \\
50 \%)\end{array}$ & Not presented \\
\hline & & & & $\begin{array}{c}100 ; 10 ; 1 ; 0.1 \mu \mathrm{g} / \mathrm{mL} \\
{[47]}\end{array}$ & $5.28 \mu \mathrm{g} / \mathrm{mL}[48]$ & Significant / strong & Not presented \\
\hline
\end{tabular}


Table 6. Cont

\begin{tabular}{|c|c|c|c|c|c|c|c|}
\hline Types Method & $\begin{array}{l}\text { Colorectal Cancer Cytotoxic } \\
\text { Analysis Method }\end{array}$ & $\begin{array}{c}\text { Types of Object/CRC } \\
\text { Cell Lines }\end{array}$ & Types of Natural Products & $\begin{array}{l}\text { The Concentration of } \\
\text { the Tested Samples }\end{array}$ & $\begin{array}{c}\text { IC50 Value / \% Cell } \\
\text { Viability / \% } \\
\text { Inhibition }\end{array}$ & $\begin{array}{c}\text { Cytotoxicity Categorize } \\
{[22]}\end{array}$ & Mechanism of Actions \\
\hline & & & \multirow{5}{*}{$\begin{array}{l}\text { Polyisoprenoids (polyprenol } \\
\text { and dolichol) from Nypa } \\
\text { fruticans, Rhizophora mucronata, } \\
\text { Ceriops tagal, Avicennia alba, } \\
\text { Avicennia marina and Avicennia } \\
\text { lanata leaves [31,32,39-41,53] }\end{array}$} & $\begin{array}{c}15.625 ; 31.25 ; 62.50 \\
125 ; 250 ; 500 \mu \mathrm{m} / \mathrm{mL} \\
{[41]}\end{array}$ & $\begin{array}{l}276 \mu \mathrm{g} / \mathrm{mL}(C . \text { tagal }) \\
\text { and } 278 \mu \mathrm{g} / \mathrm{mL}(R . \\
\text { mucronata) }[41]\end{array}$ & No cytotoxicity & \multirow{5}{*}{$\begin{array}{l}\text { Polyisoprenoids induced apoptosis } \\
\text { in the early-apoptosis phase and } \\
\text { caused cell cycle arrest in the G0-G1 } \\
\text { stage while decreasing the } \\
\text { expression of Bcl-2 and cyclin-D1. In } \\
\text { addition, the polyisoprenoid had a } \\
\text { SI value for classification as highly } \\
\text { selective and enables the } \\
\text { suppression of COX-2 expression in } \\
\text { WiDr cells [39-41]. }\end{array}$} \\
\hline & & & & $\begin{array}{c}15.625 ; 31.25 ; 62.525 \\
125 ; 250 ; 500 \mu \mathrm{g} / \mathrm{mL} \\
{[31]}\end{array}$ & $\begin{array}{l}180.2 \mu \mathrm{g} / \mathrm{mL}(\mathrm{N} . \\
\text { fruticans) }[31]\end{array}$ & Low & \\
\hline & & & & $\begin{array}{c}15.625 ; 31.25 ; 62.525 \\
125 ; 250 ; 500 \mu \mathrm{g} / \mathrm{mL} \\
{[32]}\end{array}$ & $\begin{array}{l}180.186 \mu \mathrm{g} / \mathrm{mL}(\mathrm{N} . \\
\text { fruticans) [32] }\end{array}$ & Low & \\
\hline & & & & $\begin{array}{l}500 ; 250 ; 125 ; 62.5 ; \\
31.25 \mu \mathrm{g} / \mathrm{mL}[39]\end{array}$ & $\begin{array}{c}154.987 \mu \mathrm{g} / \mathrm{mL}(A . \\
\text { marina) and 305.928 } \\
\mu \mathrm{g} / \mathrm{mL} \text { (A. lanata) }[39]\end{array}$ & Low and no cytotoxicity & \\
\hline & & & & $\begin{array}{c}500 ; 250 ; 125 ; 62.5 \\
31.25 ; 15.625 \mu \mathrm{g} / \mathrm{mL} \\
{[40]}\end{array}$ & $\begin{array}{l}173.775 \mu \mathrm{g} / \mathrm{mL}(A . \\
\quad \text { alba) }[40]\end{array}$ & Low & \\
\hline & & & $\begin{array}{l}\text { Ethyl acetate extract from } \\
\text { Trichoderma reesei strain TV221 } \\
\text { (EAFTrR) associated with } \\
\text { marine sponge: Stylissa } \\
\text { flabelliformis [41] }\end{array}$ & $\begin{array}{c}2000,1000,500 ; 400 ; \\
300 ; 250 ; 200 ; 150 ; 125 ; \\
100 ; 75 ; 62,5 ; 50 ; 25 \\
\mu \mathrm{g} / \mathrm{mL}\end{array}$ & $88.88 \mu \mathrm{g} / \mathrm{mL}$ & Low & $\begin{array}{l}\text { The extract has the potential of } \\
\text { having anti-cancer genes through } \\
\text { the capability to spur apoptosis. The } \\
\text { mechanism of inhibition of cancer } \\
\text { cell growth may go by cell cycle } \\
\text { arrest, cell cycle delay, or apoptotic } \\
\text { mechanism [42]. }\end{array}$ \\
\hline & & & $\begin{array}{l}\text { Alpinumisoflavone from } \\
\text { Erythrina poeppigiana [45] }\end{array}$ & $\begin{array}{l}100.0 ; 50.0 ; 25.0 ; 12.5 ; \\
6.25 ; 3.25 \mu \mathrm{m} / \mathrm{mL}\end{array}$ & $5.63 \mu \mathrm{g} / \mathrm{mL}$ & Significant / strong & $\begin{array}{l}\text { Alpinumisoflavone is a flavonoid } \\
\text { that has a pyran ring as } \\
\text { pyranisoflavonoid. The presence of } \\
\text { hydroxyl group in A-ring in position } \\
5 \text { increase the cytotoxic activity of } \\
\text { flavonoids. The presence of } \\
\text { hydroxyl group in B-ring in } \\
\text { positions } 4 \text { ' is shown to increase the } \\
\text { cytotoxicity of flavonoids [45]. }\end{array}$ \\
\hline & & & $\begin{array}{l}\text { Dichloromethane extract of } \\
\text { Canna indica rhizomes [30] }\end{array}$ & $\begin{array}{c}\text { 2000, 1500, 1000, 750; } \\
\text { 500; 250; } 125 \text { ppm }\end{array}$ & $361.83 \mathrm{ppm}$ & No cytotoxicity & $\begin{array}{l}\text { The extract contained a compound } \\
\text { that could induce apoptotic activity } \\
\text { and cell cycle in the WiDr cells [30]. }\end{array}$ \\
\hline & & & $\begin{array}{c}\text { Nine lichen species from six } \\
\text { different locations in East Java, } \\
\text { Indonesia [34] }\end{array}$ & $\begin{array}{c}\text { 1024, 512; } 256 ; 128 ; 64 ; \\
32 \mu \mathrm{g} / \mathrm{mL}\end{array}$ & $324 \mu \mathrm{g} / \mathrm{mL}$ & No cytotoxicity & Not presented \\
\hline
\end{tabular}


Table 6. Cont

\begin{tabular}{|c|c|c|c|c|c|c|c|}
\hline Types Method & $\begin{array}{l}\text { Colorectal Cancer Cytotoxic } \\
\text { Analysis Method }\end{array}$ & $\begin{array}{l}\text { Types of Object/CRC } \\
\text { Cell Lines }\end{array}$ & Types of Natural Products & $\begin{array}{l}\text { The Concentration of } \\
\text { the Tested Samples }\end{array}$ & $\begin{array}{l}\text { IC50 Value / \% Cell } \\
\text { Viability / \% } \\
\text { Inhibition } \\
\end{array}$ & $\begin{array}{c}\text { Cytotoxicity Categorize } \\
{[22]}\end{array}$ & Mechanism of Actions \\
\hline & & & $\begin{array}{l}\text { Arcangelisia flava L. Merr } \\
\text { chloroform extract [35] }\end{array}$ & $\begin{array}{c}\text { 50; 100; 200; } 300 ; 400 \\
\text { g/mL }\end{array}$ & $121.637 \mu \mathrm{g} / \mathrm{mL}$ & Low & $\begin{array}{l}\text { The chloroform extract of } A \text {. Flava } \\
\text { was capable to trigger apoptosis in } \\
\text { the WiDr cells [36]. }\end{array}$ \\
\hline & & & $\begin{array}{l}\text { Piper crocatum Ruiz \& Pav } \\
\text { ethanol extract [37] }\end{array}$ & $\begin{array}{l}1 ; 10 ; 100 ; 500 ; 1000 \\
2000,4000 \mu \mathrm{mg} / \mathrm{mL}\end{array}$ & $727 \mu \mathrm{g} / \mathrm{mL}$ & No cytotoxicity & $\begin{array}{l}\text { The ethanol extract of P. crocatum } \\
\text { had an activity to induce apoptosis } \\
\text { and suppress COX-2 protein } \\
\text { expression in WiDr cells [37]. }\end{array}$ \\
\hline & & & $\begin{array}{l}\text { Peptides from Platycephalus } \\
\text { fuscus [50] }\end{array}$ & $0.005 \mathrm{mg}$ protein $/ \mathrm{mL}$ & $91.04 \%$ (inhibition) & Not classified & $\begin{array}{l}\text { The further cell-based study is } \\
\text { essential to observe the mechanistic } \\
\text { pathways and structure or function } \\
\text { relationship of peptides in } \\
\text { stimulating apoptosis [50]. }\end{array}$ \\
\hline & & & $\begin{array}{l}\text { Cycloart-24-ene-26-ol-3-one } \\
\text { from Aglaia exima leaves [49] }\end{array}$ & $0.39-200 \mu \mathrm{M}$ & $\begin{array}{l}2.4 \mu \mathrm{M}(\mathrm{HT}-29) ; 5.6 \\
\mu \mathrm{M}(\mathrm{CaCo}-2)\end{array}$ & Significant / strong & $\begin{array}{l}\text { It is bound to tumor necrosis } \\
\text { factor-receptor } 1 \text { (TNF-R1) leading } \\
\text { to the initiation of caspase- } 8 \text { and, } \\
\text { through the activation of Bid, in the } \\
\text { activation of caspase- } 9 \text {. This activity } \\
\text { causes a reduction in mitochondrial } \\
\text { membrane potential (MMP) and the } \\
\text { release of cytochrome-C. The } \\
\text { activation of caspase- } 8 \text { and -9 both } \\
\text { acts to commit the cancer cells to } \\
\text { apoptosis through downstream } \\
\text { caspase- } 3 / 7 \text { activation, PARP } \\
\text { cleavage and the lack of NFkB } \\
\text { translocation into the nucleus [49]. }\end{array}$ \\
\hline & & & \multirow{3}{*}{$\begin{array}{l}\text { Seaweeds (extracted in four } \\
\text { kind of organic solvents): } \\
\text { Gracilaria verrucose [55]; Ulva } \\
\text { luctuca and Eucheuma cottonii } \\
\text { [33]; Eucheuma Sp. [46] }\end{array}$} & $\begin{array}{l}\text { 200; } 100 ; 50 ; 25 ; 12.5 ; \\
6.25 ; 3.125 ; 1.5625 \\
\text { g/mL }[55]\end{array}$ & $\begin{array}{l}43.9 \mu \mathrm{g} / \mathrm{mL}(\mathrm{G} . \\
\text { verrucose) [55] }\end{array}$ & Moderate & \multirow[t]{3}{*}{ Not presented } \\
\hline & & & & $\begin{array}{c}51.2 ; 25.6 ; 12.8 ; 6.4 ; 3.2 \\
1.6 ; 0.8 ; 0.4 \mu \mathrm{g} / \mathrm{mL} \\
{[33]}\end{array}$ & $\begin{array}{c}69.3 \mu \mathrm{g} / \mathrm{mL}(U . \\
\text { luctuca) and } 21.4 \\
\mu \mathrm{g} / \mathrm{mL}(E . \text { cottonii) } \\
{[33]}\end{array}$ & Low and moderate & \\
\hline & & & & $\begin{array}{c}51.2 ; 25.6 ; 12.8 ; 6.4 ; 3.2 \\
1.6 ; 0.8 ; 0.4 \mu \mathrm{g} / \mathrm{mL} \\
{[46]}\end{array}$ & $\begin{array}{c}16.82 \mu \mathrm{g} / \mathrm{mL} \\
\text { (Eucheuma Sp.) [46] }\end{array}$ & Significant / strong & \\
\hline
\end{tabular}


Table 6. Cont

\begin{tabular}{|c|c|c|c|c|c|c|c|}
\hline \multirow[t]{7}{*}{$\begin{array}{l}\text { Types } \\
\text { Method }\end{array}$} & $\begin{array}{l}\text { Colorectal Cancer Cytotoxic } \\
\text { Analysis Method }\end{array}$ & $\begin{array}{c}\text { Types of } \\
\text { Object/CRC Cell } \\
\text { Lines }\end{array}$ & Types of Natural Products & $\begin{array}{l}\text { The Concentration of } \\
\text { the Tested Samples }\end{array}$ & $\begin{array}{l}\text { IC50 Value / \% Cell } \\
\text { Viability } / \% \\
\text { Inhibition } \\
\end{array}$ & $\begin{array}{c}\text { Cytotoxicity } \\
\text { Categorize [22] }\end{array}$ & Mechanism of Actions \\
\hline & & & $\begin{array}{l}\text { 2-O- } \beta \text {-glucopyranosil cucurbitacin D, } \\
\text { isolated from the ethyl acetate soluble } \\
\text { fraction of Benalu batu (Begonia sp.) [29] }\end{array}$ & $\begin{array}{c}6.25 ; 12.5 ; 25 ; 50 \\
\mu \mathrm{g} / \mathrm{mL}\end{array}$ & $\begin{array}{l}0.002 \mu \mathrm{g} / \mathrm{mL} \text { and } \\
6.88 \% \text { (cell viability) }\end{array}$ & Significant / strong & $\begin{array}{l}\text { The presence of cucurbitacin type } \\
\text { triterpenoid could be a marker } \\
\text { compound for Begonia plant species. It } \\
\text { exhibited potent cytotoxic activity } \\
\text { against HCT-116 via apoptosis induction } \\
\text { with a significant percentage of early and } \\
\text { late apoptosis [29]. }\end{array}$ \\
\hline & & & $\begin{array}{l}\text { Chloroform fraction of Garcinia } \\
\text { mangostana fruits hulls [51] }\end{array}$ & $0.01-100 \mu \mathrm{M}$ & $15.8 \mu \mathrm{M}$ & Moderate & $\begin{array}{l}\text { The chloroform fraction contained } \\
\text { bioactive compounds that induced } \\
\text { significant antiproliferative and cytotoxic } \\
\text { potentials via induction of apoptosis and } \\
\text { cell cycle arrest at G0/G1-phase, necrosis, } \\
\text { and apoptosis in HCT-116 cells [51]. }\end{array}$ \\
\hline & & & $\begin{array}{l}\text { Polygonumins A from Polygonum minus } \\
\text { [35] }\end{array}$ & $\begin{array}{l}\text { 100; } 50 ; 25 ; 12.5 ; 6.25 \\
\quad 3.13 \mu \mathrm{m} / \mathrm{mL}\end{array}$ & $3.24 \mu \mathrm{g} / \mathrm{mL}$ & Significant / strong & $\begin{array}{l}\text { The sugar moiety, a sucrose unit, was } \\
\text { recognized to be critical to the } \\
\text { topoisomerase inhibition activity as } \\
\text { antitumor drugs [35]. }\end{array}$ \\
\hline & & & $\begin{array}{l}\text { Gyrinops versteegii (Gilg.) Domke leaves } \\
\text { extract (chloroform and ethanol solvents). } \\
\text { The most abundant compounds detected } \\
\text { in both extracts were fatty acids, namely } \\
\text { palmitic acid, stearic acid, and } \\
\text { pentadecanoic acid [55] }\end{array}$ & - & Not determined & - & $\begin{array}{l}\text { Not presented (the first reported study } \\
\text { on metabolite profiling of G. versteegii } \\
\text { leaves extract, the result supported } \\
\text { further study on G. versteegii as the } \\
\text { anticancer-resource plant) }\end{array}$ \\
\hline & & & $\begin{array}{c}\text { (S)-2-hydroxy-3-(octanoyloxy)propyl } \\
\text { tetracosanoate, (S)-3-(((S)-11-acetoxy } \\
\text { octadecanoyl)oxy)propane-1,2-diyl } \\
\text { diacetate, docosanedioic acid, } \\
\text { 2,5-dimethylnonadecane, lupeol, } \\
\text { stigmasterol, b-sitosterol, heptadecanoic } \\
\text { acid, hexanedioic acid, } \\
\text { 1,6-bis[(2R)-ethylhexyl] ester, and } \\
\text { 1,3-di-O-[2', } 2^{\prime} \text {-di- }(p \text {-phenylene)] were } \\
\text { isolated from the leaves of Garcinia } \\
\text { daedalanthera Pierre, collected from } \\
\text { Indonesia [56] }\end{array}$ & Not displayed & $19.2 \mu \mathrm{M}$ (lupeol) & Moderate & Not presented \\
\hline & & & $\begin{array}{l}\text { Fulvoplumierin; allamcin; allamandin; } \\
\text { 2,5-dimethoxy-p-benzoquinone; } \\
\text { plumericine; and lignan liriodendrin } \\
\text { (from bark or Plumeria rubra) [57] }\end{array}$ & Not displayed & $\begin{array}{c}0.1 \mu \mathrm{g} / \mathrm{mL} \\
\text { (plumericine); } 0.3 \\
\mu \mathrm{g} / \mathrm{mL} \text { (allamin and } \\
\text { allamandin); } 1.3 \\
\mu \mathrm{g} / \mathrm{mL} \\
\text { (fulvoplumierin); } 1.4 \\
\mu \mathrm{g} / \mathrm{mL} \\
\text { (2,5-dimethoxy-p- } \\
\text { benzoquinone); } 16 \\
\mu \mathrm{g} / \mathrm{mL} \text { (liriodendrin) }\end{array}$ & Significant / strong & Not presented \\
\hline
\end{tabular}




\section{Discussion and Future Directions}

Cancer is the second leading cause of death in the world after cardiovascular disease. Meanwhile, colorectal cancer ranks in the top three in the number of causes of death and is ranked as the second most common cancer type in men and third in women [58,59]. A comprehensive therapy development to treat colorectal cancer is needed to reduce patient mortality. This therapy development is expected to be capable of overcoming the resistance of conventional chemotherapy agents that already exist today. Resistance of WiDr cells to 5-fluorouracil (5-FU) - an antimetabolite chemotherapeutic agent-is mediated by an increased expression of thymidylate synthetase enzyme which is the main inhibitory target of 5-FU $[60,61]$. WiDr is also one of the cells that have low sensitivity to treatment with 5-FU. WiDr cells are widely applicable in Indonesia due to proper carcinogenesis and tumorigenicity studies and anti-tumor testing on potency disclosure of bioactive compounds from natural products for further development. Besides, WiDr cells are identical toHCT-15 and HT-29 cell lines because they are derived from the same patient and most likely from the same tumor [61]. Overall, WiDr cells are suitable to be used as models in screening the novel compound as a co-chemotherapeutic agent with 5-FU. Combination therapy (co-chemotherapy) of 5-FU with a chemo-preventive agent is an alternative to overcome resistance, increase efficacy, and reduce adverse effects. These facts that lead the research and development of natural products become important for the future directions of medicinal plants in colorectal cancer therapy.

Plants are one of the largest sources of natural products that are used to discover and develop novel chemotherapeutic agents. In particular, several discovered novel compounds from plants have unique mechanisms of action, greater efficacy, or lower adverse effects compared to the conventional chemotherapy drugs currently in use. Bioactive compounds from medicinal plants in Indonesia have also been studied to exhibit anticancer activities in the colorectal, namely terpenoids, phytosterols, alkaloids, phenolics, flavonoids, and polyisoprenoids (the basic structure for one of several derivatives from those bioactive compounds is presented in Figure 2).

As previously described in the research on the anti-colorectal cancer mechanism of polyisoprenoid compounds, polyisoprenoid was able to inhibit the colorectal cancer cells proliferation through up-regulation mechanisms, i.e., increased p53 gene expression (generating the cancer cell cycle blockade), induced apoptosis, and through down-regulation mechanisms, i.e., inhibition of PI3K gene expression, AKT1 gene, mTOR gene, and inhibition of EGF receptor expression [39,53]. The increase of p53 gene expression played a key role in response to cellular stress, for example, exposure to carcinogens, and also inhibited the proliferation of abnormal cells that have initiated carcinogens to prevent the development of neoplasms. The p53 gene also regulated apoptosis, inhibited angiogenesis, and regulated DNA repairment. According to the previous investigation, the increased level of the polyisoprenoid dose was able to provide a significantly increased percentage of p53 expression [48]. In addition, polyisoprenoid also has the potential to inhibit colorectal cancer cell metastasis through blockade of COX-2 expression [40,52]. It seems that colorectal cancer in Indonesia is still far beyond common understanding and more gene expression studies are needed to reveal the heterogeneous mechanisms of its process.

In the current paper, we conducted a systematic review that provided predictions for several secondary metabolites sourced from natural products to be utilized as an alternative treatment against colorectal cancer in Indonesia. They are also prospective candidates for future co-chemotherapy agents in safety, quality, standardization, and efficaciousness. This finding emphasized the potential of several natural products as anticancer agents against colorectal cancer cells.

The rich biodiversity of Indonesian plants derived from tropical rainforests provides a diversity of structural compounds that can be used as anti-colorectal cancer agents. At the same time, this review challenged Indonesian researchers of colorectal cancers to support drug-independence programs as these national products can be a part of the competitive multinational market. The utilization of Indonesia's natural resources, which are rich in 
plant biodiversity, seems to be less than optimal compared to the number of traditional medicines that have been proven to have benefits and are scientifically proven. Indonesia has more than 30,000 species of plants and animals that have the potential as medicines and 9,600 species of plants and animals that are known to have medicinal properties. This potential can be developed to meet the growing demand for traditional medicines and health supplements based on natural ingredients [62,63].

Traditional medicine in Indonesia is popular with the name Јати. Јати is usually used as a plant that has medicinal properties and has served various Indonesian generations for centuries. The Indonesian government categorizes traditional medicinal preparations into three categories, namely Jamu, standardized herbal medicine, and fitofarmaka (phytomedicine). Herbal medicine is categorized as a traditional medicine that has been used empirically but has not yet been scientifically tested; standardized herbal medicine are those plants with medicinal properties that have been proven by preclinical testing; fitofarmaka is a medicinal plant that has been tested to the clinical stage. Until 2019, 23 natural products have been registered and have been proven in clinical trials. Therefore, they are categorized as fitofarmaka in Indonesia [63,64].<smiles>C=C(C)C1CCC2(C)CCC3C(CCCC3(C)C)C12CCC1C(C)CCC(O)C1(C)C</smiles>

Lupeol (terpenoid)<smiles>CN[C@@H](C)C(O)c1ccccc1</smiles>

Ephedrine (Alkaloids)

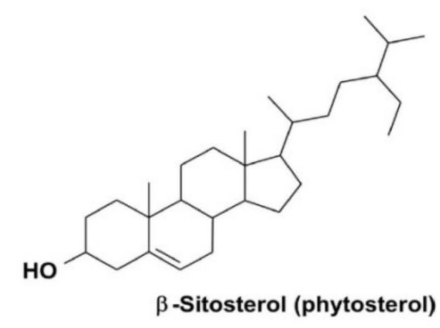<smiles>O=c1cc(-c2ccccc2)oc2ccccc12</smiles><smiles></smiles>

Summary of SAR for phenolic-induced antioxidant

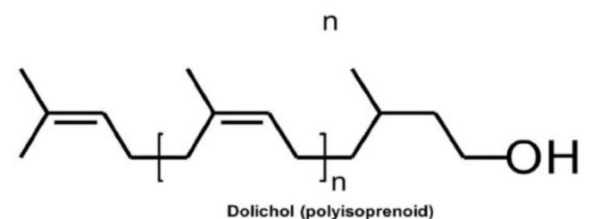

Figure 2. The basic structure for one of the various derivatives from bioactive compounds of terpenoids, phytosterols, alkaloids, phenolics, flavonoids, and polyisoprenoids.

Herbal medicine has become a part of the culture in Indonesia. This has been done for generations. Its use in the long term has proven its safety and benefits empirically in the community. Despite having been used for centuries, herbal medicine had no place 
in the formal healthcare system in Indonesia before 1987. Since 1988, the Indonesian government, through the Ministry of Health, has been regulating and encouraging efforts to use scientific Јатu as an alternative and additional medicine. The Indonesian government has also established a body under the name Directorate of Traditional, Alternative, and Complementary of Health Care (BINA YANKES TRADKOM) [65-67]. However, in practice, the use of traditional medicine informal medicine is not a priority and is even avoided sometimes. This is due to the absence of guidelines, legal basis for use, and support within the Health Insurance Agency in Indonesia [68]. Another reason for this may be because the dose of the natural product to date to induce cytotoxicity is less than established chemotherapy. Therefore, there is a need to look for a highly toxic natural compound that may be conjugated to cancer antigen-specific antibodies. Designing a clinical trial to test the efficacy of adding herbal products in combination with chemotherapy is also a challenge. Many herbal compounds demonstrate antioxidant activity which contradicts the mechanism of chemotherapy, which is generally a pro-oxidant agent.

Leading the discovery is the main component of today's early pharmaceutical research. The exploration of novel drugs for colorectal cancer therapy that has a fast progression can be a drug repurposing strategy to bypass preclinical steps that usually require laborious and resource-intensive work. In addition, it is also considered that the development of existing agents in the future can be more easily utilized by the community. For those purposes, the exploration of Indonesia's frequently used natural resources biodiversity is the best choice. In the past, drug development is based on trial and error, so it was costly and time-consuming. Today, molecular modeling, with the aid of computer hardware and software (computational method), has reduced the risk and the process of discovery is more effective in cost and time [69].

Molecular docking is the computational simulation of a ligand binding to a receptor, which helps to predict binding molecule to the protein target to predict the affinity and activity. The aim of target discovery is the identification and validation of suitable drug targets for therapeutic intervention. Structure-based drug design (SBDD) is responsible for the toxicity and activity of a compound in the body. The SBDD utilizes information from the target protein structure to find the active site of the protein that binds to the drug compound. This is a challenge for a natural product such as Jamu which is generally not a pure compound. There is a need to purify and synthesize specific compounds that are originally derived from exotic plants to conserve the environment. Based on the prediction of the active site, compounds can be designed with the expectations to bind to the target protein and have biological activity. These techniques support those novel drug developments which have specific activities by the mechanism of drug-receptor interaction. Computer-aided drug design (CAAD) helps to identify small molecules by orienting and scoring them in the active binding site of a protein [70].

In silico approaches contribute significantly to early pharmaceutical research and are especially important in target discovery and its lead. The need for timely adaptation and application of in silico approaches in pharmaceutical research has been recognized to design and discover novel active substances better than previous compounds and is expected to improve further the overall efficiency of drug discovery [71].

\section{Conclusions}

In summary, this review revealed bioactive compounds from natural products of Indonesian plants that have been researched and have potential as anticancer agents that are most commonly experienced in men and women including colorectal cancer. The general method used for the analysis of the cytotoxic activity of colorectal cancer cells is the in vitro method using the MTT assay, the most widely used cell line is WiDr. The most studied bioactive compounds that have any activity against colorectal cancer are terpenoids, phytosterols, phenolics, alkaloids, and polyisoprenoids, but other natural products may have the potential to be developed from this study. 
Author Contributions: Conceptualization, M.B., D.N.I. and I.H.; methodology, D.N.I., M.B., I.H. and O.M.; validation, formal analysis, and investigation, D.N.I., M.B., I.H. and O.M.; resources, M.B.; data curation, D.N.I., I.H. and M.B.; writing—original draft preparation, D.N.I. and M.B.; writing—review and editing, D.N.I., M.B., I.H., O.M., A.R.H.U., G.A.S. and A.N.; visualization, D.N.I.; supervision, M.B., A.R.H.U. and A.N.; project administration, M.B.; funding acquisition, M.B. All authors have read and agreed to the published version of the manuscript.

Funding: This research and APC was funded by the Directorate of Research and Community Service, the Ministry of Education, Culture, Research, and Technology of the Republic of Indonesia through the World-Class Research Program 2021 (No. 214/SP2H/AMD/LT/DRPM/2020).

Institutional Review Board Statement: Not applicable.

Informed Consent Statement: Not applicable.

Data Availability Statement: No additional data is available for this paper.

Conflicts of Interest: The authors declare no conflict of interest.

\section{References}

1. WHO. Latest Global Cancer Data: Cancer Burden Rises to 18.1 Million New Cases and 9.6 Million Cancer Deaths in 2018. Available online: https:/ /www.who.int/cancer/PRGlobocanFinal.pdf (accessed on 14 May 2021).

2. Kuipers, E.J.; Grady, W.M.; Lieberman, D.; Seufferlein, T.; Sung, J.J.; Boelens, P.G.; van de Velde, C.J.H.; Watanabe, T. Colorectal Cancer. Nat. Rev. Dis. Prim. 2015, 5, 15065. [CrossRef]

3. Aakif, M.; Balfe, P.; Elfaedy, O.; Awan, F.N.; Pretorius, F.; Silvio, L.; Castinera, C.; Mustafa, H. Study on Colorectal Cancer Presentation, Treatment and Follow-Up. Int. J. Colorectal Dis. 2016, 31, 1361-1362. [CrossRef]

4. $\quad$ Leung, W.K.; Ho, K.Y.; Kim, W.; Lau, J.Y.W.; Ong, E.; Hilmi, I.; Kullavanijaya, P.; Wang, C.; Li, C.; Fujita, R.; et al. Colorectal Neoplasia in Asia: A Multicenter Colonoscopy Survey in Symptomatic Patients. Gastrointest. Endosc. 2006, 64, 751-759. [CrossRef]

5. Ng, S.C.; Zeng, Z.; Niewiadomski, O.; Tang, W.; Bell, S.; Kamm, M.A.; Hu, P.; de Silva, J.; Niriella, M.A.; Udara, W.S.A.A.Y.; et al. Early Course of Inflammatory Bowel Disease in a Population-Based Inception Cohort Study from 8 Countries in Asia and Australia. Gastroenterology 2016, 150, 86-95. [CrossRef]

6. Abdullah, M.; Sudoyo, A.W.; Utoma, A.R.; Fauzi, A.; Rani, A.A. Molecular Profile of Colorectal Cancer in Indonesia: Is There Another Pathway? Gastroenterol. Hepatol. Bed Bench 2012, 5, 71-78.

7. Conze, D.; Weiss, L.; Regen, P.S.; Bhushan, A.; Weaver, D.; Johnson, P.; Rincon, M. Autocrine Production of Interleukin 6 Causes Multidrug Resistance in Breast Cancer Cells. Cancer Res. 2001, 61, 8851-8858. [PubMed]

8. Shapiro, G.I.; Harper, J.W. Anticancer Drug Targets: Cell Cycle and Checkpoint Control. J. Clin. Investig. 1999, $104,1645-1653$. [CrossRef] [PubMed]

9. Kitagawa, S. Inhibitory Effects of Polyphenols on P-Glycoprotein-Mediated Transport. Biol. Pharm. Bull. 2006, 29, 1-6. [CrossRef]

10. Adina, A.B.; Goenadi, F.A.; Handoko, F.F.; Nawangsari, D.A.; Hermawan, A.; Jenie, R.I.; Meiyanto, E. Combination of Ethanolic Extract of Citrus Aurantifolia Peels with Doxorubicin Modulate Cell Cycle and Increase Apoptosis Induction on MCF-7 Cells. Iran. J. Pharm. Res. 2014, 13, 919-926. [PubMed]

11. Sudiana, I.K. Patobiologi Molekular Kanker; Salemba Medika: Jakarta, Indonesia, 2008.

12. Knödler, M.; Buyel, J.F. Plant-Made Immunotoxin Building Blocks: A Roadmap for Producing Therapeutic Antibody-Toxin Fusions. Biotechnol. Adv. 2021, 47, 107683. [CrossRef]

13. Cragg, G.M.; Newman, D.J. A Tale of Two Tumor Targets: Topoisomerase I and Tubulin. The Wall and Wani Contribution to Cancer Chemotherapy. J. Nat. Prod. 2004, 67, 232-244. [CrossRef]

14. Stohrl, W.R. The Role of Natural Products in a Modern Drug Discovery Program. Drug Discov. Today 2000, 5, 39-41. [CrossRef]

15. Methley, A.M.; Campbell, S.; Chew-Cheraghi-Sohi, C. PICO, PICOS and SPIDER: A Comparison Study of Specificity and Sensitivity in Three Search Tools for Qualitative Systematic Reviews. BMC Health Serv. Res. 2014, 14, 1-10. [CrossRef]

16. Johnson, B.T.; Hennessy, E.A. Systematic Reviews and Meta-Analyses in the Health Sciences: Best Practice Methods for Research Syntheses. Soc. Sci. Med. 2019, 233, 237-251. [CrossRef]

17. Charrois, T.L.; Durec, T.; Tsuyuki, R.T. Systematic Reviews of Pharmacy Practice Research: Methodologic Issues in Searching, Evaluating, Interpreting, and Disseminating Results. Ann. Pharmacother. 2009, 43, 118-122. [CrossRef] [PubMed]

18. Munn, Z.; Peters, M.D.J.; Stern, C.; Tufanaru, C.; McArthur, A.; Aromataris, E. Systematic Review or Scoping Review? Guidance for Authors When Choosing between a Systematic or Scoping Review Approach. BMC Med. Res. Methodol. 2018, 18, 1-7. [CrossRef] [PubMed]

19. Chen, T.R.; Drabkowski, D.; Hay, R.J.; Macy, M.; Peterson, W., Jr. WiDr Is a Derivative of Another Colon Adenocarcinoma Cell Line, HT-29. Cancer Genet. Cytogenet. 1987, 27, 125-134. [CrossRef]

20. Waly, M.I.; Al-Rawahi, A.S.; Al Riyami, M.; Al-Kindi, M.A.; Al-Issaei, H.K.; Farooq, S.A.; Al-Alawi, A.; Rahman, M.S. Amelioration of Azoxymethane Induced-Carcinogenesis by Reducing Oxidative Stress in Rat Colon by Natural Extracts. BMC Complement. Altern. Med. 2014, 14, 1-10. [CrossRef] 
21. Reddy, B.S. Animal Models for Colon Cancer Chemoprevention. In Encyclopedia of Cancer; Bertino, J.R., 2nd, Ed.; Elsevier Science: New York, NY, USA, 2002; Volume 1, pp. 49-55. [CrossRef]

22. Kuete, V.; Efferth, T. African Flora Has the Potential to Fight Multidrug Resistance of Cancer. BioMed Res. Int. 2015, $2015,914813$. [CrossRef] [PubMed]

23. Tanaka, T.; Sugie, S. Inhibition of Colon Carcinogenesis by Dietary Non-Nutritive Compounds. J. Toxicol. Pathol. 2007, 20, 215-235. [CrossRef]

24. Shwter, A.N.; Abdullah, N.A.; Alshawsh, M.A.; El-Seedi, H.R.; Al-Henhena, N.A.; Khalifa, S.A.M.; Abdulla, M.A. Chemopreventive Effect of Phaleria Macrocarpa on Colorectal Cancer Aberrant Crypt Foci in vivo. J. Ethnopharmacol. 2016, 193, 195-206. [CrossRef] [PubMed]

25. Nurdin, S.U.; Le Leu, R.K.; Aburto-Medina, A.; Young, G.P.; Stangoulis, J.C.R.; Ball, A.S.; Abbott, C.A. Effects of Dietary Fibre from the Traditional Indonesian Food, Green Cincau (Premna Oblongifolia Merr.) on Preneoplastic Lesions and Short Chain Fatty Acid Production in an Azoxymethane Rat Model of Colon Cancer. Int. J. Mol. Sci. 2018, 19, 2593. [CrossRef] [PubMed]

26. Tatsuta, T.; Hosono, M.; Rotinsulu, H.; Wewengkang, D.S.; Sumilat, D.A.; Namikoshi, M.; Yamazaki, H. Lissoclibadin 1, a Polysulfur Aromatic Alkaloid from the Indonesian Ascidian Lissoclinum Cf. Badium, Induces Caspase-Dependent Apoptosis in Human Colon Cancer Cells and Suppresses Tumor Growth in Nude Mice. J. Nat. Prod. 2017, 80, 499-502. [CrossRef] [PubMed]

27. Yamazaki, H.; Wewengkang, D.S.; Nishikawa, T.; Rotinsulu, H.; Mangindaan, R.E.P.; Namikoshi, M. Two New Tryptamine Derivatives, Leptoclinidamide and (-)-Leptoclinidamine B, from an Indonesian Ascidian Leptoclinides Dubius. Mar. Drugs 2012, 10, 349-357. [CrossRef]

28. Arifni, F.R.; Hasan, A.E.Z.; Julistiono, H.; Bermawie, N.; Riyanti, E.I. Anticancer Activities of Endophytic Fungi Isolated from Soursop Leaves (Annonamuricata L.) against WiDr Cancer Cells. Annu. Res. Rev. Biol. 2017, 18, 1-11. [CrossRef]

29. Zubair, M.S.; Alarif, W.M.; Ghandourah, M.A.; Anam, S.; Jantan, I. Cytotoxic Activity of 2-o- $\beta$-Glucopyranosil Cucurbitacin d from Benalu Batu (Begonia Sp.) Growing in Morowali, Central Sulawesi. Indones. J. Chem. 2020, 20, 766-772. [CrossRef]

30. Widyarini, S.; Hartanto, N.L.; Pratiwi, R. Phytochemical Analysis and Cytotoxic Activities of Two Distinct Cultivars of Ganyong Rhizomes (Canna Indica) against the Widr Colon Cancer Cell Line. Biodiversitas 2020, 21, 1660-1669. [CrossRef]

31. Sari, D.P.; Basyuni, M.; Hasibuan, P.A.Z.; Sumardi, S.; Nuryawan, A.; Wati, R. Cytotoxic and Antiproliferative Activity of Polyisoprenoids in Seventeen Mangroves Species against WiDr Colon Cancer Cells. Asian Pac. J. Cancer Prev. 2018, 19, 3393-3400. [CrossRef]

32. Sari, D.P.; Basyuni, M.; Hasibuan, P.A.Z.; Wati, R. The Inhibition of Polyisoprenoids from Nypa Fruticans Leaves on Cyclooxygenase 2 Expression of WiDr Colon Cancer Cells. Asian J. Pharm. Clin. Res. 2018, 11, 154-157. [CrossRef]

33. Arsianti, A.; Fadilah, F.; Wibisono, L.K.; Kusmardi, S.; Azizah, N.N.; Putrianingsih, R.; Murniasih, T.; Rasyid, A.; Pangesti, R. Phytochemical Composition and Anticancer Activity of Seaweeds Ulva Lactuca and Eucheuma Cottonii against Breast MCF-7 and Colon HCT-116 Cells. Asian J. Pharm. Clin. Res. 2016, 9, 115-119. [CrossRef]

34. Nugraha, A.S.; Pratoko, D.K.; Damayanti, Y.D.; Lestari, N.D.; Laksono, T.A.; Addy, H.S.; Untari, L.F.; Kusumawardani, B.; Wangchuk, P. Antibacterial and Anticancer Activities of Nine Lichens of Indonesian Java Island. J. Biol. Act. Prod. Nat. 2019, 9 , 39-46. [CrossRef]

35. Ahmad, R.; Sahidin, I.; Taher, M.; Low, C.; Noor, N.M.; Sillapachaiyaporn, C.; Chuchawankul, S.; Sarachana, T.; Tencomnao, T.; Iskandar, F.; et al. Polygonumins A, a Newly Isolated Compound from the Stem of Polygonum Minus Huds with Potential Medicinal Activities. Sci. Rep. 2018, 8, 1-15. [CrossRef]

36. Ariati, V. Uji Sitotoksisitas Dan Apoptosis Ekstrak Kloroform Daun Kayu Kuning (Arcangelisia Flava, L. Merr) Terhadap Kultur Sel Kanker Kolon WiDr In Vitro. Undergraduate Thesis, Universitas Jember, Jember, East Java, Indonesia, 2015.

37. Utami, M.T. Pengaruh Ekstrak Etanolik Daun Sirih Merah (Piper Crocatum Ruiz and Pav) Terhadap Sel Kanker Kolon WiDr. Sanata Darma University, Yogyakarta, Indonesia, 2015.

38. Artasasta, M.A.; Yanwirasati, A.D.; Handayani, D. Cytotoxic Activity Screening of Ethyl Acetate Fungal Extracts Derived from the Marine Sponge Neopetrosia ChaliniformisAR-01. J. Appl. Pharm. Sci. 2017, 7, 174-178. [CrossRef]

39. Illian, D.N.; Basyuni, M.; Wati, R.; Hasibuan, P.A.Z. Polyisoprenoids from Avicennia Marina and Avicennia Lanata Inhibit WiDr Cells Proliferation. Pharmacogn. Mag. 2018, 14, 513-518. [CrossRef]

40. Illian, D.N.; Hasibuan, P.A.Z.; Sumardi, N.A.; Wati, R.; Basyuni, M. Anticancer Activity of Polyisoprenoids from Avicennia Alba Blume. in WiDr Cells. Iran. J. Pharm. Res. 2019, 18, 1477-1487.

41. Sari, D.P.; Basyuni, M.; Hasibuan, P.A.Z.; Wati, R. Cytotoxic Effect of Polyisoprenoids from Rhizophora Mucronata and Ceriops Tagal Leaves against WiDr Colon Cancer Cell Lines. Sains Malays. 2018, 47, 1953-1959. [CrossRef]

42. Setyowati, E.P.; Pratiwi, S.; Purwatiningsih, P.I. In-Vitro Cytotoxicity and Apoptosis Mechanism of Ethyl Acetate Extract from Trichoderma Reesei Strain TV221 Associated with Marine Sponge: Stylissa Flabelliformis. J. Appl. Pharm. Sci. 2018, 8, 151-157. [CrossRef]

43. Sumilat, D.A.; Wewengkang, D.S.; Rotinsulu, H.; Yamazaki, H.; Oda, T.; Ukai, K.; Namikoshi, M. Bioactivity of Extracts from Ascidians Collected in North Sulawesi as Seeds of Marine-Derived Drugs. AACL Bioflux 2018, 11, 516-524.

44. Aminah, I.; Putra, A.E.; Arbain, D.; Handayani, D. Screening of Cytotoxic Activities toward WiDr and Vero Cell Lines of Ethyl Acetate Extracts of Fungi Derived from the Marine Sponge Acanthostrongylophora Ingens. J. Appl. Pharm. Sci. 2019, 9, 1-5. [CrossRef] 
45. Herlina, T.; Haraswati, N.; Apriani, R.; Nishinarizki, V.; Gaffar, S.; Supratman, U. Cytotoxic Activity of Alpinumisoflavone from Erythrina Poeppigiana (Leguminosae) Against Colon Cancer (WiDr), Cervical Cancer (Hela), and Hepatoma Cancer (HepG2) Cells. HAYATI J. Biosci. 2019, 26, 96-100. [CrossRef]

46. Subroto, P.A.M.; Arsianti, A.; Lesmana, E. Phytochemical Analysis and Anticancer Activity of Seaweed Eucheuma Sp. against Colon HCT-116 Cells. 3rd Biomedical Engineering's Recent Progress in Biomaterials, Drugs Development, and Medical Devices: Proceedings of the International Symposium of Biomediacal Enginering (ISBE) 2018, Jakarta, Indonesia, 6-8 August 2018; Gozan, M., Astutiningsih, S., Wulan, P.P.D.K., Ramahdita, G., Dhelika, R., Kreshanti, P., Eds.; AIP Conference Proceedings: Jakarta, Indonesia, 2019; Volume 2092, p. 030015. [CrossRef]

47. Artasasta, M.A.; Yanwirasti, T.M.; Djamaan, A.; Handayani, D. Cytotoxic and Antibacterial Activities of Marine Sponge-Derived Fungus Aspergillus Nomius NC06. Rasayan J. Chem. 2019, 12, 1463-1469. [CrossRef]

48. Insanu, M.; Anggadiredja, J.; Kayser, O. Curcacycline A and B-New Pharmacological Insights to an Old Drug. Int. J. Appl. Res. Nat. Prod. 2012, 5, 26-34.

49. Leong, K.H.; Looi, C.Y.; Loong, X.M.; Cheah, F.K.; Supratman, U.; Litaudon, M.; Mustafa, M.R.; Awang, K. Cycloart-24-Ene26-Ol-3-One, a New Cycloartane Isolated from Leaves of Aglaia Exima Triggers Tumour Necrosis Factor-Receptor 1-Mediated Caspase-Dependent Apoptosis in Colon Cancer Cell Line. PLoS ONE 2016, 11, 1-17. [CrossRef]

50. Nurdiani, R.; Vasilijevic, T.; Yeager, T.; Singh, T.K.; Donkor, O.N. Bioactive Peptides with Radical Scavenging and Cancer Cell Cytotoxic Activities Derived from Flathead (Platycephalus Fuscus) by-Products. Eur. Food Res. Technol. 2017, $243,627-637$. [CrossRef]

51. Mohamed, G.A.; Al-Abd, A.M.; El-Halawany, A.M.; Abdalla, H.M.; Ibrahim, S.R.M. New Xanthones and Cytotoxic Constituents from Garcinia Mangostana Fruit Hulls against Human Hepatocellular, Breast, and Colorectal Cancer Cell Lines. J. Ethnopharmacol. 2017, 23, 302-312. [CrossRef]

52. Istiqomah, M.A.; Hasibuan, P.A.Z.; Sumardi, S.; Nuryawan, A.; Wati, R.; Basyuni, M. Apoptotic with Double-Staining Test, P53, and Cyclooxygenase-2 to Proliferation Colon Cancer Cell (WiDr) of Dolichol in Three Mangrove Leaves. Open Access Maced. J. Med. Sci. 2020, 8, 37-42. [CrossRef]

53. Istiqomah, M.A.; Hasibuan, P.A.Z.; Sumaiyah, S.; Yusraini, E.; Oku, H.; Basyuni, M. Anticancer Effects of Polyisoprenoid From Nypa Fruticans Leaves by Controlling Expression of P53, EGFR, PI3K, AKT1, and MTOR Genes in Colon Cancer (WiDr) Cells. Nat. Prod. Commun. 2020, 15, 1-8. [CrossRef]

54. Forestrania, R.C.; Anaya-Eugenio, G.D.; Acuña, U.M.; Ren, Y.; Elya, B.; de Blanco, E.C. Secondary Metabolites from Garcinia Daedalanthera Pierre Leaves (Clusiaceae). Nat. Prod. Res. 2020, 1-7. [CrossRef] [PubMed]

55. Wardana, T.A.P.; Nuringtyas, T.R.; Wijayanti, N.; Hidayati, L. Phytochemical Analysis of Agarwood (Gyrinops Versteegii (Gilg.) Domke) Leaves Extracts as Anticancer Using GC-MS. In Proceedings of the 2nd International Conference on Science, Mathematics, Environment, and Education, Surakarta, Indonesia, 26-28 July 2019; AIP Conference Proceedings: Surakarta, Indonesia, 2019; Volume 2194, p. 020136. [CrossRef]

56. Kurniasari, K.D.; Arsianti, A.; Astika, Y.; Mandasari, B.K.D.; Masita, R.; Zulfa, F.R.; Dewi, M.K.; Zagloel, C.R.Z.; Azizah, N.N.; Putrianingsih, R. Phytochemical Analysis and Anticancer Activity of Seaweed Gracilaria Verrucosa against Colorectal HCT-116 Cells. Orient. J. Chem. 2018, 34, 1257-1262. [CrossRef]

57. Kardono, L.B.S.; Tsauri, S.; Padmawinata, K.; Pezzuto, J.M.; Kinghorn, A.D. Cytotoxic Constituents of the Bark of Plumeria Rubra Collected in Indonesia. J. Nat. Prod. 1990, 53, 1447-1455. [CrossRef]

58. Kimman, M.; Norman, R.; Jan, S.; Kongston, D.; Woodward, M. The Burden of Cancer in Member Countries of the Association of Southeast Asian Nations (ASEAN). Asian Pac. J. Cancer Prev. 2012, 13, 411-420. [CrossRef] [PubMed]

59. McDonald, M.; Hertz, R.P.; Lowenthal, S.W.P. The Burden of Cancer in Asia. Available online: https://cdn.pfizer.com/pfizercom/ products / cancer_in_asia.pdf (accessed on 14 May 2021).

60. Sigmond, J.; Backus, H.H.J.; Wouters, D.; Temmik, O.H.; Jansen, G.; Peters, G.J. Induction of Resistance to the Multitargeted Antifolate Pemetrexed (ALIMTA) in WiDr Human Colon Cancer Cells Is Associated with Thymidylate Synthase Overexpression. Biochem. Pharmacol. 2003, 66, 431-438. [CrossRef]

61. Ahmed, D.; Eide, P.W.; Eilertsen, I.A.; Danielsen, S.A.; Eknaes, M.; Hektoen, M.; Lind, G.E.; Lothe, R.A. Epigenetic and Genetic Features of 24 Colon Cancer Cell Lines. Oncogenesis 2013, 2, e71. [CrossRef] [PubMed]

62. BPOM. Dorong Percepatan Pengembangan Industri Fitofarmaka, Bdan POM Sampaikan Strategi Tingkat Global. Available online: https://www.pom.go.id/new/view/more/pers/484/Dorong-Percepatan-Pengembangan-Industri-Fitofarmaka--BadanPOM-Sampaikan-Strategi-di-Tingkat-Global.html (accessed on 14 May 2021).

63. BPOM. Potensi Obat Herbal Indonesia. Available online: https://www.pom.go.id/new/view/more/pers/531/Potensi-ObatHerbal-Indonesia.html (accessed on 14 May 2021).

64. Elfahmi, W.H.J.; Woerdenbag, H.; Kayser, O.; Handayani, L. Jamu: Indonesian Traditional Herbal Medicine towards Rational Phytopharmacological Use. J. Herb. Med. 2014, 4, 51-73. [CrossRef]

65. Handayani, L.; Suparto, H.; Suprapto, A. Traditional System of Medicine in Indonesia. In Traditional Medicine in Asia; Chaudhury, R.R., Rafei, U.M., Eds.; WHO Regional Office for South-East Asia: New Delhi, India, 2001; pp. 47-68. 
66. Husain, F.; Wahidah, B.F. Traditional Medicine and Medical Pluralism in Eastern Indonesia (A Literature Review). In The 5th International Conference on Education \& Social Sciecnces (ICESS) "The Asia Network: Bringing Time, Space and Social Life Together", Sydney, Australia, 11-13 December 2017; Singh, B., Talib, K.A., Weintre, J., Wasino, Eds.; Fakultas Ilmu Sosial, Universitas Negeri Semarang: Semarang, Indonesia, 2017; pp. 198-205.

67. WHO. National Policy on Traditional Medicine and Regulation of Herbal Medicines: Report of a WHO Global Survey; WHO: Geneva, Switzerland, 2005.

68. Kurniawan, R.A.; Aprilianto, S. The Integration Traditional Medicine Practice at National Health Insurance in Indonesia. In Proceedings of the International Law Conference (iN-LAC 2018)—Law, Technology and the Imperative of Change in the 21st Century, Surabaya, Indonesia, 4-5 September 2018; pp. 13-17. [CrossRef]

69. Noolvi, M.N.; Patel, H.M.; Bhardwaj, V.; Chauhan, A. Synthesis and in vitro Antitumor Activity of Substituted Quinazoline and Quinoxaline Derivatives: Search for Anticancer Agent. Eur. J. Med. Chem. 2011, 46, 2327-2346. [CrossRef]

70. Jayaraj, R.L.; Ranjani, V.; Manigandan, K.; Elangovan, N. Insilico Docking Studies to Identify Potent Inhibitors of Alpha-Synuclein Aggregation in Parkinson Disease. Asian J. Pharm. Clin. Res. 2013, 6, 127-131.

71. Terstappen, G.C.; Reggiani, A. In silico Research in Drug Discovery. Trends Pharmacol. Sci. 2001, 22, 23-26. [CrossRef] 